\title{
Suppression of Fires Exposed to an External Radiant Flux
}

\author{
Michelle K. Donnelly \\ William L. Grosshandler \\ Building and Fire Research Laboratory \\ Gaithersburg, Maryland 20899
}
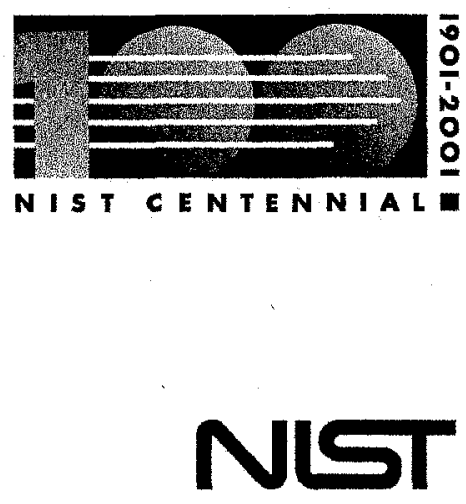

National Institute of Standards and Technology Technology Administration, U.S. Department of Commerce 



\title{
Suppression of Fires Exposed to an External Radiant Flux
}

\author{
Michelle K. Donnelly \\ William L. Grosshandler \\ Building and Fire Research Laboratory \\ Gaithersburg, Maryland 20899
}

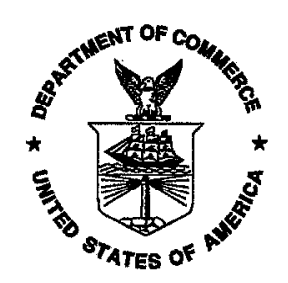

U.S. Department of Commerce

Donald L. Evans, Secretary

Technology Administration

Phillip J. Bond, Under Secretary for Technology

National Institute of Standards and Technology Arden L. Bement, Jr., Director 


\section{ABSTRACT}

When materials burn in the presence of a continuous, external energy source, they are often more difficult to extinguish and may require an increase in suppression agent concentration to extinguish the fire. This situation could exist for class $\mathrm{C}$ fires involving electrically energized wires that cannot be de-energized. There is a need for data to determine what increase in extinguishing agent concentration is necessary when the external energy source cannot be powered off.

In response to this, a Radiantly Enhanced Extinguishing Device (REED) was developed to examine the amount of agent necessary to suppress the fire as a function of the flux from an external energy source. The design for the REED is based on the design of the standard cup burner apparatus identified in the NFPA 2001 Standard on Clean Agent Fire Extinguishing Systems (NFPA, 2000). While the cup burner is designed for use with liquid or gaseous fuels, the REED tests solid fuels.

Five fuel materials were tested: poly methyl methacrylate (PMMA), polypropylene, acrylonitrile butadiene styrene (ABS), polyvinyl chloride (PVC), and ethylene propylene diene terpolymer (EPDM). Nitrogen was used as the suppression agent for all of the materials tested. The results showed that the amount of agent needed to suppress the fire increased as the radiant flux on the fuel increased. In some cases, the amount of suppressant needed reached a plateau for the flux levels tested. For the materials evaluated, the amount of nitrogen needed to extinguish the sample at the higher heat fluxes was greater than the heptane cup burner value for nitrogen. The results demonstrate the impact extra radiant energy can have on extinguishing a fire, and the need for data to predict how much extra agent to use in these situations. The REED apparatus provides a method for collecting suppression data for fire exposed to an external flux.

\section{INTRODUCTION}

The presence of an external energy source can have a significant impact on the behavior of a fire. Experiments studying the ignition of gaseous fuels have found that the amount of suppression agent required to prevent ignition is significantly more when the fuel is exposed to an energized heated surface (Braun, 1999). Other tests have shown that burning materials which are exposed to these external energy sources can be more difficult to extinguish, and may require a considerable increase in the amount of agent to suppress the fire (Driscoll and Rivers, 1996). In some cases, the continuous energy source can also prompt a re-ignition of the material after suppression.

Because of these hazards, there is a need to quantify the fire enhancing effects of continuous energy sources. The Radiant Enhanced Extinguishing Device (REED) was developed to provide the necessary data to determine amounts of agent needed to extinguish fires and prevent re-ignition in these situations. The apparatus allows for burning materials to be subjected to a controlled radiant flux while the flow of air and extinguishing agent is regulated. A photograph of a sample of EPDM being tested in the REED is shown in Figure 1.

The NFPA 2001 Standard on Clean Agent Fire Extinguishing Systems defines Class C fires in chapter 1-3.7 as "Fire that involves energized electrical equipment where the electrical resistivity of the extinguishing media is of importance." For class $\mathrm{C}$ fires, in particular, electrically energized wires generate heat, creating a continuous source of energy in addition to the fire's own energy. The NFPA 2001 Standard currently recommends eliminating the power to 
electrical equipment involved in a class $C$ fire, whenever possible. In a real life fire scenario, equipment may take a long time to de-energize, and in some cases it may not be possible or desirable to completely turn off the power. The NFPA 2001 Standard addresses this issue in appendix A-3-6, which states:

"Energized electrical equipment that could provide a prolonged ignition source should be de-energized prior to or during agent discharge. If electrical equipment cannot be de-energized, consideration should be given to the use of extended agent discharge, higher initial concentration, and the possibility of the formation of combustion and decomposition products. Additional testing can be needed on suppression of energized electrical equipment fires to determine these quantities."

The remainder of appendix A-3-6 describes examples of methods that may be used to perform this additional testing. The REED apparatus has been designed as a method to quantify the suppression of fires with an external energy source. The design for the REED is based on the design of the standard cup burner apparatus in the NFPA 2001 Standard, appendix B (NFPA, 2000) with modifications to allow testing of solid fuels and exposure to an external radiant flux.

\section{EQUIPMENT}

The REED is designed to support a burning sample underneath a heater, while supplying desired gases to the system. A block diagram of the equipment is shown in Figure 2. Gas flows of air, nitrogen and suppression agents are regulated by three rotameters mounted on a control panel. The gases are carried through a combination of copper and polypropylene tubing to the sample support and chimney apparatus. A conical heater located above the chimneys supplies continuous, external energy to the burning sample. The temperature of the heater is monitored and regulated by a temperature controller. A flux gage measures the radiant flux on the sample and the results are displayed on a digital multimeter.

The REED is modeled after the cup burner apparatus, which is the NFPA standard for determining extinguishing concentrations of liquid and gaseous fuels. A schematic of the cup burner, listing the important dimensions, is shown in Figure 3. The cup burner is comprised of an elevated cup located inside a glass or quartz chimney. The liquid or gaseous fuel is supplied to an opening in the bottom of the cup by flowing up through the tube that supports the cup. The fuel is ignited at the top of the cup. Air is premixed with an extinguishing agent. The mixture is passed through a diffuser and flows inside the chimney. The amount of extinguishing agent is slowly increased until the flame is extinguished. A detailed description of the standard cup burner and the testing procedure are included in the NFPA 2001 Standard (NFPA, 2000).

The elements of the REED were designed to closely emulate the cup burner apparatus, with modifications to accommodate solid fuels and an external heating element. A diagram of the REED is shown in Figure 4. The device has an inner chimney and outer chimney, with a sample support post in the center. The inner chimney has the same diameter, $85 \mathrm{~mm}$, as the chimney of the cup burner. It also serves the same function as the chimney of the cup burner, delivering the air and agent to the flame. In both the REED and the cup burner, a diffuser is located beneath the chimney to evenly distribute the flow of gases. The support post is styled after the cup section of the cup burner. The $31 \mathrm{~mm}$ diameter at the top of the post falls within the 
range for cup diameters. The support post has a height of $235 \mathrm{~mm}$ above the diffuser, which is the same height as the cup in the cup burner device.

The main differences between the REED and the cup burner come from the need to accommodate solid fuel and the addition of a radiant heating element. In the cup burner, the liquid and gas fuels are supplied continuously to the cup during the testing process. Since the REED burns solid materials, it requires that the solid fuel material be placed on the support post and ignited at the start of the test. To allow access to this post, each chimney is made in two pieces with a removable top section connected to the lower section by a plastic ring. The inner lip on the ring is flush with the sides of the glass so the gas flow is not disturbed. The addition of a radiant heating source required the size of the chimney above the flame to be much shorter than the chimney used in the cup burner experiments. In order to achieve the desired heat flux on the sample, the heater needed to be placed very close above the sample. While the chimney of the cup burner extends $300 \mathrm{~mm}$ above the top of the cup, the chimney on the REED only reaches $75.4 \mathrm{~mm}$ above the top of the support post, allowing for the heater to be positioned close to the burning sample.

The apparatus used to obtain the results for this paper is a second-generation REED. During the previous phase of this project, an initial REED was built and evaluated to determine the feasibility of testing solid fuels in a device similar to the cup burner (Steckler, et al. 1998). Based on these results, the design was revised for ease of operation and to more closely resemble the cup burner. For the second-generation REED, the inner diameter of the innermost glass chimney was increased from $76 \mathrm{~mm}$ in the previous apparatus to $85 \mathrm{~mm}$ in the new device, which conforms to the cup burner dimension. The inner diameter of the external chimney was decreased from $124 \mathrm{~mm}$ in the old apparalus to $99 \mathrm{~mm}$ in the new assembly. This significantly reduces the size of the annulus between the two chimneys, reducing the amount of nitrogen co-flow needed. The second-generation REED also incorporates the flux gage into the design, which fixes the gage location improving its accuracy. The first-generation REED included a load cell for mass loss measurements, but this was eliminated in the subsequent design.

The REED is comprised of two concentric glass chimneys surrounding a sample support post, all centered on a circular base. The base and the support post are made of stainless steel. The support post is tapered, starting with a diameter of $15 \mathrm{~mm}$ at its base, and spreading out to a $31 \mathrm{~mm}$ diameter at the top. At the bottom of the inner chimney is a diffuser, which contains a combination of fine screens and $6 \mathrm{~mm}$ diameter glass beads and has a height of $76 \mathrm{~mm}$. A mixture of air and extinguishing agent enters the diffuser through a hole in the circular base and is distributed throughout for an even flow in the chimney. Nitrogen co-flow enters the annulus between the two chimneys through the circular base as well. Stainless steel wool placed between the chimneys disperses the nitrogen throughout the annulus.

A rod-shaped Medtherm ${ }^{1}$ heat flux gage, model number 16-10SB-17-36-21339, with a diameter of $6.35 \mathrm{~mm}$ is mounted in the hollow of the support post. Cooling water is supplied to the flux gage through Nalgene tubing. An arm attached to the end of the rod, below the chimney base, allows the gage to be raised above and lowered inside the support post. The top of the support post has a $12.7 \mathrm{~mm}$ cup shaped depression. A hole in the center of the depression allows the flux gage to pass through and keeps the gage centered while taking flux measurements. During testing, the gage is lowered inside the support post and a $12.7 \mathrm{~m}$ thick maranite disk is

\footnotetext{
${ }^{1}$ Certain trade names and company products are mentioned in the text or identified in an illustration in order to specify adequately the experimental procedure and equipment used. In no case does such identification imply recommendation or endorsement by the National Institute of Standards and Technology, nor does it imply that the products are necessarily the best available for the purpose.
} 
placed in the depression. The disk reduces heat transfer from the metal support post to the bottom of the sample. The flux gage reading was measured using a digital multimeter.

A radiant heater identical to the one used with the standard cone calorimeter method (ISO 5660) is used to supply the radiant energy to the sample. The conical heater measures $90 \mathrm{~mm}$ across the top and $160 \mathrm{~mm}$ along its base. It is positioned at a height of $84.5 \mathrm{~cm}$ above the top of the sample support post. This allows for a $9.1 \mathrm{~mm}$ clearance between the bottom of the heater and the top of the glass chimneys. Three type $\mathrm{K}$ thermocouples are located at various locations in the heater to monitor the temperature. The thermocouple readings are averaged together and a temperature controller (Omega series CN9000A) regulates the average temperature of the heater.

An aluminum frame holds the parts of the apparatus together. The circular base holding the chimneys and support post is mounted on a movable platform that slides along two rails of the aluminum frame. This allows the set-up to slide from underneath the heater in order to remove the chimney tops for sample positioning and replace them after lighting. The aluminum framework holds the heater in its fixed position above the chimneys. It also elevates the circular base so the flux gage may be raised and lowered. The entire apparatus is located inside a chemical fume hood.

\section{TESTING PROCEDURES}

The first step in the testing procedure was to prepare the samples of the material to be tested. Samples were cut from cylindrical rods $25.4 \mathrm{~mm}$ in diameter. Each sample was cut to a height of $25.4 \mathrm{~mm}$. The samples were then wrapped, either with aluminum foil or with paperboard, to help them maintain a cylindrical shape while burning. Materials that melted were placed in the center of a piece of foil, which was then folded up around the sample to form a cup shape. For charring materials, a strip of paperboard was wrapped to form a cylinder around the sample, and was secured with a thin wire to control the rate at which the edges burned. There was no paperboard on the bottom of the samples.

Before testing, the laboratory temperature and barometric pressure were recorded and used to calculate the rotameter settings for the desired air flow. Next the temperature for the conical heater was selected and the heater was turned on. Once the heater had reached the set temperature, the support post section, with all parts of the chimneys in place, was slid under the heater. The flux gage was raised, the air flow initiated, and the flux level at the location of the sample top was measured. The flux gage was then lowered inside the support post and the equipment slid from under the heater so the chimneys could be removed. The maranite disk was placed in the top of the post and the prepared sample was centered on the support post. With the air still flowing, the sample was ignited using the propane torch. When the flame was fully established, the glass chimneys were put back in place and the apparatus was repositioned under the heater.

The sample was allowed to burn without any extinguishing agents present for $200 \mathrm{~s}$ before a suppression agent was introduced. Each increment of agent-air mixture was allowed $30 \mathrm{~s}$ to take effect before the agent volume fraction was increased. The amount of suppression agent was slowly increased until the flame was extinguished. What remained of the sample was removed and its height measured. With the air and agent still flowing, the heat flux gage was then raised to the height where extinction occurred, and the heat flux was measured. 


\section{RESULTS}

Experiments with the new apparatus were performed using a variety of materials. All experiments were conducted with bottled nitrogen as the suppression agent. Tests were conducted for increasing radiant flux levels for each material. With the previous testing device, the radiant energy flux was always measured at the position of the initial sample height, $25.4 \mathrm{~mm}$ above the top of the sample support post. The new design of the apparatus allows for the flux level at any height to be measured easily. This enables flux measurements to be taken at the location of extinction, based on the sample height at extinction. Because the polymers either reduced in height as they burned, or increased in height as they charred, the height of the sample, and thus the flux it experienced at extinction was often quite different from the flux measured at the unburned sample height. Depending on the flux level and the material, samples changed in height as much as $10 \mathrm{~mm}$, resulting in a flux changes as much as $4.3 \mathrm{~kW} / \mathrm{m}^{2}$ different from the flux at the start of the test.

\section{Preliminary Tests with PMMA}

Tests to characterize the new apparatus were conducted using poly methyl methacrylate (PMMA) as the fuel. PMMA was chosen for the preliminary testing of the new system because it is easy to ignite and retains its shape while burning. $\Lambda$ dditionally, PMMA was used successfully with the previous REED apparatus. Preliminary experiments in the new device examined the impact of flow rates, preburn times, sample preparation and exhaust issues on the minimum extinguishment volume fractions.

The NFPA 2001 Standard on Clean Agent Fire Extinguishing Systems calls for each cup burner test to be conducted at air flow rates of $10 \mathrm{~L} / \mathrm{min}, 20 \mathrm{~L} / \mathrm{min}, 30 \mathrm{~L} / \mathrm{min}, 40 \mathrm{~L} / \mathrm{min}$ and $50 \mathrm{~L} / \mathrm{min}$ to determine where the extinguishing volume fraction is maximum (NFPA, 2000). In the previous phase of this project, mass loss data were examined for various air flows with no agent present, and consequently a rate of $10 \mathrm{~L} / \mathrm{min}$ was selected for these tests. For the current work, the impact of air flow rates during actual extinction tests was studied. Nitrogen extinction experiments were conducted on PMMA for air flow rates of $10 \mathrm{~L} / \mathrm{min}, 20 \mathrm{~L} / \mathrm{min}, 30 \mathrm{~L} / \mathrm{min}$, and $40 \mathrm{~L} / \mathrm{min}$, all at the zero flux condition. A plot of the results is shown in Figure 5. The data show that the volume fraction of nitrogen necessary for extinction decreases as the flow rate of air is increased. The greatest extinction volume fractions for nitrogen, thus the most suppression material needed, occurred when the air flow rate was $10 \mathrm{~L} / \mathrm{min}$. Here the extinction volume fraction was 0.225 , with a relative combined standard uncertainty of $\pm 12 \%$. Because the greatest amount of suppression material was needed with air flow rates of $10 \mathrm{~L} / \mathrm{min}$, all further nitrogen testing was done with air flows of $10 \mathrm{~L} / \mathrm{min}$. For reference, the cup burner value for nitrogen, with heptane as the fuel, is 0.30 ( \pm .03 ) (Sheinson, et al. 1989).

A variety of conditions were examined to determine which factors had an impact on the results and which factors were less critical. In the previous phase of the project, a preburn time of $200 \mathrm{~s}$ was selected to allow the firc to fully establish itself before suppression was attempted. This time was selected based on the burning rate of PMMA. For the new device, we examined the effect of reducing the preburn time to just $60 \mathrm{~s}$. Results from the tests with the $60 \mathrm{~s}$ preburn time fell within the scatter of the data collected with a $200 \mathrm{~s}$ preburn. This did not appear to be a significant factor. The effect of the wrapping material was also examined in the new apparatus. 
Data were collected with PMMA samples wrapped first with aluminum foil, and then with paperboard. The results were virtually identical for both sets of data.

The REED apparatus was originally located on the bench top with an exhaust hood directly overhead. Because some of the materials selected create toxic decomposition products when they are burned, the decision was made to move the apparatus into a fume hood. After the move was completed, data were again taken with PMMA and nitrogen. The results obtained were consistent with the previous results outside the fume hood.

The apparatus was designed with an inner and outer chimney. The inner chimney carries the air and suppression agent to the sample. The outer chimney is designed to carry a nitrogen co-flow to protect the heater from hydrogen fluoride or hydrogen chloride, which are combustion products of many of the suppression agents. When nitrogen is used as the suppression agent, there is no hydrogen fluoride or hydrogen chloride formed so it is not necessary to use the nitrogen co-flow to protect the heater. Data collected for nitrogen tests run with and without the co-flow showed the presence of a co-flow made no difference in the results.

Figure 6 shows a comparison between data acquired using the old apparatus, and data obtained using the new apparatus for PMMA with nitrogen as the suppression agent. To remain. consistent, only tests conducted with $10 \mathrm{~L} / \mathrm{min}$ air flows and a preburn of $200 \mathrm{~s}$ are included in the figure. When the flux on the sample was zero, the two devices gave very similar results of the required extinction volume fraction. However, when a flux was applied to the sample, the nitrogen volume fraction required for extinction was lower in the new apparatus than in the old apparatus. Experiments conducted in the second-generation device have extinction values that are approximately $20 \%$ to $25 \%$ lower than the previous results. Although the testing procedure was similar, the geometry of the two devices is different, which may affect results. Also, heat flux measurements in the old apparatus were always taken at the initial sample height, not the height at extinction, so the flux measured for PMMA would be higher than the flux on the sample at the time of extinction.

\section{Other Materials}

After the preliminary testing with PMMA was finished, experiments were then conducted on four different materials: polypropylene, ABS, PVC and EPDM. Specifications for these materials are listed in Table 1 . An air flow of $10 \mathrm{~L} / \mathrm{min}$ and a preburn time of $200 \mathrm{~s}$ were used for all tests. Nitrogen was used as the extinguishing agent for all of these tests, thus the nitrogen co-flow in the outer chimney was not activated. Some of the materials were difficult to ignite, so modifications to the procedure were necessary and are discussed in each section. The results for each material tested include uncertainties from measurements, temperature conditions, and scatter in the data. These matters are discussed in later sections. The overall results from these tests show that the amount of agent needed for suppression increases as the imposed heat flux increases. 
Table 1. Materials used for samples

\begin{tabular}{|l|l|l|l||}
\hline MATERIAL & TYPE & SPECIFICATIONS & $\begin{array}{l}\text { DENSITY } \\
\left(\mathrm{g} / \mathrm{cm}^{3}\right)\end{array}$ \\
\hline $\begin{array}{l}\text { Poly methyl } \\
\text { methacrylate } \\
\text { (PMMA) }\end{array}$ & Cast rod, rigid & Federal Specification L-P-391 & 1.19 \\
\hline Polypropylene & $\begin{array}{l}\text { Extruded rod, semi- } \\
\text { rigid }\end{array}$ & Federal Specification L-P-394 & 0.91 \\
\hline $\begin{array}{l}\text { Acrylonitrile } \\
\text { butadiene styrene } \\
\text { (ABS) }\end{array}$ & Annealed rod, rigid & $\begin{array}{l}\text { General Electric's Cyclolac GSE } \\
\text { Resin }\end{array}$ & 1.04 \\
\hline $\begin{array}{l}\text { Poly vinyl } \\
\text { chloride (PVC) }\end{array}$ & $\begin{array}{l}\text { Exruded rod, Type 1 } \\
\text { Grade 1, rigid PVC }\end{array}$ & $\begin{array}{l}\text { ASTM Standard 1784-81 } \\
\text { Federal Specification L-P-535e }\end{array}$ & 1.45 \\
\hline $\begin{array}{l}\text { Ethylene } \\
\text { propylene diene } \\
\text { terpolymer } \\
\text { (EPDM) }\end{array}$ & $\begin{array}{l}\text { Flexible, durometer of } \\
70\end{array}$ & $\begin{array}{l}\text { ASTM standard D2000-98 } \\
\text { M3BA710A14B13C12F19 }\end{array}$ & 1.14 \\
\hline
\end{tabular}

\section{Polypropylene}

Because its heat distortion temperature is very low, $104 \mathrm{EC}$, polypropylene burned as a liquid during these tests. To contain the samples, the polypropylene was wrappcd in foil, but as it melted it expanded and spilled over the side of the foil wrap. To prevent this from happening, the foil cup was constructed so that a lip about $5 \mathrm{~mm}$ high was left at the top of the cup. The polypropylene completely melted during the test and then cooled back to a solid after the heat was removed. Figure 7 is a photograph of a polypropylene sample being tested in the REED.

The polypropylene was particularly difficult to ignite and often went out shortly after it was lit, before the chimneys could be put in place. Because of this, a technique was developed using PMMA slices to ignite the polypropylene. Thin discs of PMMA (nominally1 $\mathrm{mm}$ to $2 \mathrm{~mm}$ ) were placed on top of the polypropylene and lit. As the PMMA burned, the chimneys could easily be put in place and the whole apparatus could then be slid under the heater allowing the polypropylene to ignite while exposed to the flux. It was easy to tell when the polypropylene had ignited because there was a dramatic difference between the burning PMMA and the burning polypropylene. The PMMA burned with a relatively small flame and a small amount of smoke. The polypropylene however, had a much larger and unsteady flame and gave off a great deal of thick, black smoke.

A graph of the nitrogen extinction data for polypropylene is shown in Figure 8. With no heat flux on the sample, a nitrogen volume fraction of 0.09 is needed to extinguish the fire. For flux levels between $0 \mathrm{~kW} / \mathrm{m}^{2}$ and $20 \mathrm{~kW} / \mathrm{m}^{2}$ the extinction volume fraction increases as the flux level increases. Above $20 \mathrm{~kW} / \mathrm{m}^{2}$, the required extinction volume fraction of nitrogen levels off slightly above 0.50 . This is about $67 \%$ higher than the nitrogen cup burner value for heptane. 


\begin{abstract}
ABS
Acrylonitrile butadiene styrene (ABS) was chosen as a test material because it chars as it burns. The char tended to expand upwards especially on the outer edges of the sample. The burning ABS also gave off black droplets, which condensed on the sides of the glass chimney. The ABS samples were wrapped in foil before testing to prevent the samples from losing their shape when they were heated. As the ABS sample burned, a bowl-shaped indentation formed in the center of the bottom of the sample. Like the PMMA, the ABS could be lit directly with the propane torch. However, it was not possible to maintain the ABS burning when the flux level was zero. Figure 9 is a photograph of an ABS sample after testing, showing the charring on the top of the sample.

A graph of the nitrogen extinction volume fraction data for ABS is shown in Figure 10. The nitrogen extinction volume fraction increased steadily for fluxes between $2 \mathrm{~kW} / \mathrm{m}^{2}$ and $20 \mathrm{~kW} / \mathrm{m}^{2}$. At flux values above $20 \mathrm{~kW} / \mathrm{m}^{2}$, the concentration of nitrogen needed for extinction reaches a plateau at a volume fraction of about 0.47 .
\end{abstract}

\title{
PVC
}

Extinction tests were attempted using poly vinyl chloride (PVC) as the fuel. The PVC was very difficult to ignite, and would remain lit only under very high fluxes. Using the propane torch, it was not possible to light the PVC directly. PMMA discs were placed on the PVC samples and lit in order to ignite the PVC. In most cases, the PVC either did not ignite, or extinguished during the preburn, before any suppression agent was added.

The PVC which did burn gave off huge amounts of thick black smoke and had a wide, deep orange flame, surrounded by bright yellow jagged flame on the bottom. Quick flashes of small, very bright sparks frequently could be seen in the orange flame. All of the PVC charred quickly during the burning, even the pieces that did not sustain a flame for long. The samples were wrapped in foil in an attempt to maintain the shape, but as it charred, the PVC expanded in both the vertical and horizontal directions, forcing the foil out of the cylindrical shape. The two samples that did manage to burn long enough to extinguish with nitrogen almost doubled in topside surface area, which may have helped them to sustain the flames. Figure 11 shows a top and side view of a PVC sample after testing. The deformities caused by the charring and expanding of the PVC during burning can easily be seen.

A graph of the PVC data is shown in Figure 12. The circles plotted at the zero extinction volume fraction represent attempts to ignite the PVC. Each circle represents at least several attempts at that flux setting. Only two of the $18 \mathrm{PVC}$ samples stayed lit long enough to run a test. One of these samples ignited at a flux of $40 \mathrm{~kW} / \mathrm{m}^{2}$ and increased in height as it charred so that the flux at extinction was $44 \mathrm{~kW} / \mathrm{m}^{2}$. Several attempts were made to repeat this data point, but the additional samples would not remain lit at the same conditions. The temperature of the heater was then increased to $900{ }^{\circ} \mathrm{C}$, the maximum limit for this particular instrument. Four attempts were made at this setting before a PVC sample finally ignited. $\Lambda \mathrm{fter}$ this sample was extinguished, it reignited when the nitrogen was eliminated. It required a slightly higher volume fraction of nitrogen to extinguish it the second time. At the flux selling of $60 \mathrm{~kW} / \mathrm{m}^{2}$ there are two extinction points shown on the graph for this one sample. 


\section{EPDM}

The last material tested was ethylene propylene diene terpolymer (EPDM). Like ABS, EPDM is a material that chars when it burns, however the characteristics were very different. The EPDM char did not significantly expand upward or harden like the ABS. Instead the EPDM char was very ashy and fell apart easily when touched. The extinguished samples resembled glowing embers of wood in a fireplace, because even though the flames were extinguishcd and the sample was removed from the radiant heat, an orange glimmer could be seen behind the char as the EPDM continued to smolder for up to thirty minutes after the test.

As with the polypropylene, it was not possible to ignite the EPDM using the propane torch; therefore, the technique of lighting thin slices of PMMA on top of the samples was used to ignite the EPDM. The clear PMMA could easily be seen on top of the dark EPDM and one could visually distinguish when all of the PMMA had been consumed and the EPDM was ignited. The EPDM samples were tested using three different preparation methods: foil wrapped, paperboard wrapped, and unwrapped. For the unwrapped samples, the preburn time was reduced to only $100 \mathrm{~s}$ because the flames traveled so far down the sides of the sample that a longer preburn would have resulted in the entire sample enflamed.

Results of the EPDM testing are shown in Figure 13. The black circles represent tests conducted with a foil wrap around the EPDM, the gray squares show testing done with paperboard wrap, and the open diamonds show tests done with unwrapped samples of EPDM. The results indicate that for low fluxes, the fire was very sensitive to the type of wrap used. At a flux of $10 \mathrm{~kW} / \mathrm{m}^{2}$, it was possible to run an extinction test for the unwrapped sample, but the paperboard wrapped sample extinguished itself before completing the preburn. Also, at $10 \mathrm{~kW} / \mathrm{m}^{2}$, the foil wrapped sample would not ignite at all. When the flux was increased to about $20 \mathrm{~kW} / \mathrm{m}^{2}$, the foil wrapped samples were still difficult to ignite and extinguished themselves during pre-burn two out of three times tested. The paperboard wrapped and unwrapped samples were able to be tested, but data obtained for all samples at this flux level were very scattered. For flux levels near and above $30 \mathrm{~kW} / \mathrm{m}^{2}$, all of the samples ignited easily and the results obtained at these settings did not appear to depend on the type of wrap used. Extinction volume fractions obtained at these higher flux levels were consistent with one another, regardless of how the sample was wrapped. For EPDM, the extinction volume fraction of nitrogen required continued to increase as the flux levels increased, and did not reach a leveling off for the flux range available with this apparatus. With the exception of PVC, the EPDM required less nitrogen for suppression of the fire than the other materials tested.

\section{TEMPERATURE MEASUREMENTS}

The temperature of the air flowing past the sample may affect the extinction results. A higher temperature of air flow may allow a flame to exist for volume fractions of extinguishing agent where it may have gone out at a lower temperature. To investigate possible temperature changes, measurements of the air temperature inside the inner chimney were made using a type $\mathrm{K}$, grounded thermocouple. The thermocouple was encased in a stainless steel sheath with a diameter of $0.508 \mathrm{~mm}$. It was inserted through the midpoint of the polymer band, $55.5 \mathrm{~mm}$ below the top of the support post and $140 \mathrm{~mm}$ below the bottom of the conical heater. Most of the measurements were taken $10 \mathrm{~mm}$ in from the chimney wall, although temperatures at other depths were also measured. 
The measured temperatures were affected by both time and radiation, which made it difficult to identify the actual temperature for the air inside the chimney. The temperature was a function of the length of time the apparatus was under the heater and it continually increased as the time increased. After $20 \mathrm{~min}$, which is much longer than most of the tests, the measured temperature was still steadily rising. The actual air temperature was difficult to determine because the thermocouple was affected by radiation from the heater, which caused it to read a higher temperature than the air actually was. The thermocouple shield attempted to block this radiation, but eventually the shield itself heated up and radiated to the thermocouple. Figure 14 shows an example temperature trace, this one measured $10 \mathrm{~mm}$ inside the glass chimney with a flux of $30 \mathrm{~kW} / \mathrm{m}^{2}$ at the initial sample height. At times less than zero, the REED apparatus is not under the heater, and the temperature is slightly above $30^{\circ} \mathrm{C}$, which is the same as the ambient temperature inside the hood. When the apparatus is then positioned under the heater, the thermocouple reading immediately rises to $55^{\circ} \mathrm{C}$, an increase of more than $20^{\circ} \mathrm{C}$. Since the moving air is not heated by that magnitude that quickly, the immediate increase in temperature is mostly the effect of radiation from the heater on the thermocouple. This effect can be seen again when the apparatus is moved out from under the heater (around $600 \mathrm{~s}$ on graph). When the device is removed from the heater, the temperature instantly registers $18{ }^{\circ} \mathrm{C}$ lower. This immediate drop in the thermocouple reading due to the removal of the radiation is then followed by the less severe decrease in actual temperature due to the cooling of the apparatus. The apparent temperature reported by the thermocouple is $18^{\circ} \mathrm{C}$ to $23^{\circ} \mathrm{C}$ higher than the actual temperature.

Disregarding the immediate jump in thermocouple reading due to radiation, Figure 14 shows that while exposed to the conical heater, the air temperature continues to increase at a constant rate. This is evident by the fairly linear relationship between the time and temperature during heat-up. Since the air is constantly flowing through the system, the air is warmed not by the heater, but by convection from the hot walls of the glass chimney. As the glass chimney remains under the heater, its temperature increases, and consequently the air flowing by it gets hotter as well, for the time period investigated. After the REED is moved from under the heater, there is a slow cooling of the chimney walls and thus the air flowing past them. This decrease in temperature is much slower than the preceding temperature increase, as indicated by the gradual slope of the curve. If tests are run in close succession, the apparatus may not have completely cooled from the previous test, and therefore the second test may be run with a slightly pre-heated apparatus. Figure 15 demonstrates this with two identical tests that result in slightly different temperature traces. For the lower trace, the apparatus was completely cooled and thus placed under the heater from a cold start. For the upper trace, the apparatus started off pre-heated by two degrees, and remained two or three degrees hotter throughout the test. This shows that if the device is warm at the start of the test, the air temperature during the test will be higher than if the device was completely cool to start. However, this difference in initial temperature does not seem to impact the results much, because the experiments conducted without the heater exhibited the same amount of scatter and uncertainty as the experiments done using the heater, which may have varying starting temperatures. 


\section{UNCERTAINTY ANALYSIS}

The data collected during these tests are subject to uncertainties from radiant flux and flow measurements, and from repeatability. A small uncertainty in the measurement of the nitrogen volume fraction is introduced by uncertainties in the measurements of the flows. Rotameters were used to control the flow of the air, nitrogen co-flow, and nitrogen suppression agent. The rotameters were calibrated for the individual gases using a bubble flow meter (Gilibrator-2 soap-film flow meter) with a relative standard uncertainty of $\pm 1 \%$. Corrections based on the laboratory temperature and barometric pressure were made on a daily basis and the input pressure of the gases was regulated. The relative standard uncertainty associated with the repeatability of the rotameter flow using these calibration curves was found to be $\pm 0.5 \%$ of the flow. The total propagated relative standard uncertainty for the calculated nitrogen volume fraction is $\pm 1.2 \%$.

Uncertainties in the measurement of the radiant flux also affect the extinction volume fraction. The heat flux gage has a relative standard uncertainty of $\pm 1.5 \%$ as claimed by the manufacturer. Measurements of the radiant flux were taken at the sample height, to the nearest millimeter, and with a voltage reading resolution of $\pm 0.05 \mathrm{mV}$. This converts to a radiant flux reading with a relative standard uncertainty of $\pm 2.6 \%$. The total relative standard uncertainty for the radiant flux measurement is then $\pm 3.0 \%$. This uncertainty in the flux measurement propagates to the extinction volume fraction and the propagated uncertainty is dependent on the flow at extinction as a function of the flux for each material. The propagated relative standard uncertainty for a flux relative uncertainty of $\pm 3.0 \%$ is calculated to be $\pm 1.9 \%$ of the extinction volume fraction.

These uncertainties from the flux and flow measurements are small when compared to the uncertainties calculated from the repeatability of the tests. Experiments repeated with the same testing conditions were found to have a relative standard uncertainty of $\pm 11.9 \%$. This shows the most significant source of uncertainty in the results is from repeatability. The relative combined standard uncertainty including repeatability, flow and flux for the extinction volume fraction at a given flux is $\pm 12 \%$. Based on a coverage factor of 2 ( $95 \%$ confidence interval) the relative expanded uncertainty for the volume fraction of nitrogen is estimated to be $\pm 24 \%$.

\section{CONCLUSIONS}

These experiments successfully demonstrate that the second-generation REED may be used to evaluate the effects of external radiant energy on the suppression of a fire. $\Lambda$ variety of tests were conducted to select appropriate operating conditions. Five solid materials were tested over a range of external heat fluxes. For all of the materials tested, the amount of agent needed to suppress the fire increased as the flux on the fuel increased. For the PMMA, polypropylene and $\mathrm{ABS}$, the extinction volume fraction of nitrogen exceeded the heptane cup burner value of 0.30 when fluxes as low as $15 \mathrm{~kW} / \mathrm{m}^{2}$ were applied to the sample. For the PVC and EPDM, this cup burner value was also exceeded, at fluxes above $40 \mathrm{~kW} / \mathrm{m}^{2}$. Suppression systems currently using the standard of using the cup burner value plus $20 \%$ may not provide enough agent to extinguish fires exposed to these radiant flux levels.

Nitrogen volume fractions required for extinction varied with the type of material. For polypropylene and $\mathrm{ABS}$ the extinction volume fraction leveled off around 0.50 even with 
increasing flux values. The nitrogen extinction volume fraction for PMMA and EPDM continued to increase as the flux increased for flux ranges tested with this device. Most of the PVC samples did not burn long enough to test. A heater with a higher flux range would be needed to adequately test PVC. The PMMA, polypropylene and ABS required similar amounts of nitrogen to extinguish the samples for the flux levels tested. The EPDM was easier to suppress, needing less nitrogen than the other samples at the same flux levels. The dominant source of uncertainty for these expcriments is from the repcatability of the tests. Including all uncertainty sources, the relative combined standard uncertainty for the extinction volume fraction at a chosen heat flux is $\pm 12 \%$. Based on a coverage factor of 2 (95\% confidence interval) the relative expanded uncertainty for the volume fraction of nitrogen is $\pm 24 \%$. The ambient air temperature was measured and found to increase with the device's exposure to the conical heater. These differences in the air temperature did not seem to significantly impact the results, however, because tests run without the heater had similar scatter to tests run with the healer.

This project was successful in showing the REED can be used to evaluate the extinction of materials exposed to an external heat flux. Now opportunity exists to further this work by examining the interaction of various sample materials with different extinguishing agents and collecting more data on a variety of materials. The experiments conducted in the first-generation apparatus used PMMA as the sample material and used different gaseous extinguishing agents. For all of the tests discussed in this paper, nitrogen was used as the extinguishing agent and the sample material was varied. The next step would be to conduct experiments with different combinations of sample materials and gaseous agents using the REED. The overall goal of this project is to compile data for suppression as a function of the flux, which may be used as reference when designing suppression systems.

\section{ACKNOWLEDGEMENT}

This work was supported in part by a CRADA with the $3 \mathrm{M}$ corporation.' The assistance of Paul Rivers, from 3M is appreciated. Thanks and recognition to Ken Steckler for his work designing the second generation REED. The authors would also like to thank Michael Selepak for his contributions to the assembly of the project equipment and apparatus. 


\section{REFERENCES}

ISO 5660. Fire Tests - Reaction to Fire - Part 1: Rate of Heat Release from Building Products (Cone Calorimeter Method). International Standards Organization, Geneva, 1993.

NFPA 2001. Standard on Clean Agent Fire Extinguishing Systems. National Fire Protection Association, Quincy, MA, 1996.

Braun, E., Womeldorf, C.A., and Grosshandler, W.L. "Suppression concentration of clean agents exposed to a continuously energized heated metal surface," Fire Safety Journal, Vol. 33, pp.141$152,1999$.

Driscoll, M. and Rivers, P., "Clean Extinguishing Agents and Continually Energized Circuits," National Institute of Standards and Technology Annual Conference on Fire Research: Book of Abstracts. October 28-31, 1996, NISTIR 5904; pp. 51-52, 1996.

Sheinson, R.S., Penner-Hahn, J.E., and Indritz, D. "The Physical and Chemical Action of Fire Suppressants," Fire Safety Journal, Vol. 15, pp. 437-450, 1989.

Steckler, K., Grosshandler, W., Smith, D. and Rivers, P. "Clean Agent Performance on Fires Exposed to an External Energy Source," National Institute of Standards and Technology Annual Conference on Fire Research: Book of Abstracts. November 2-5, 1998, NISTIR 6242; pp. 127128, 1998. 


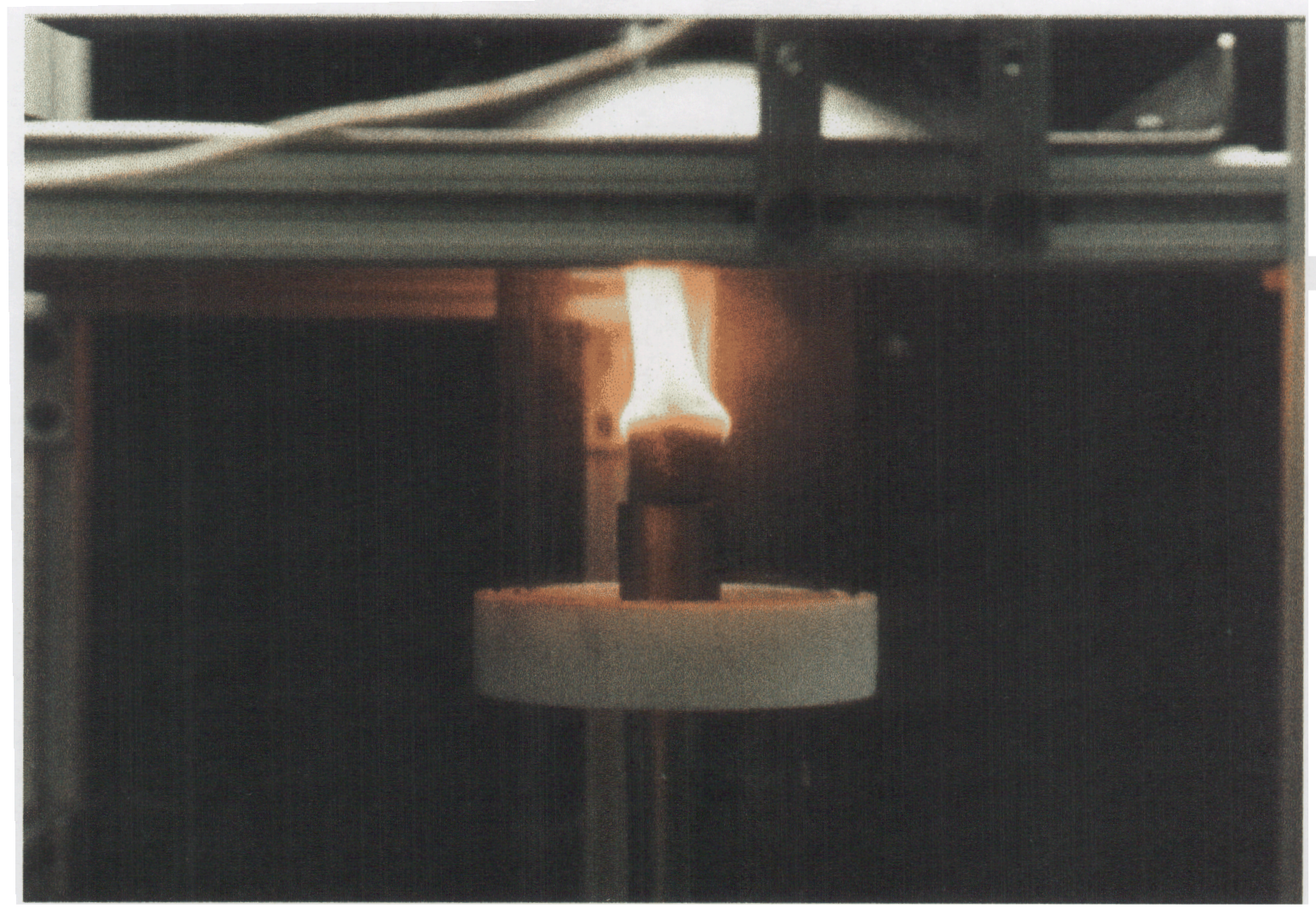

Figure 1. EPDM burning in the REED apparatus. 

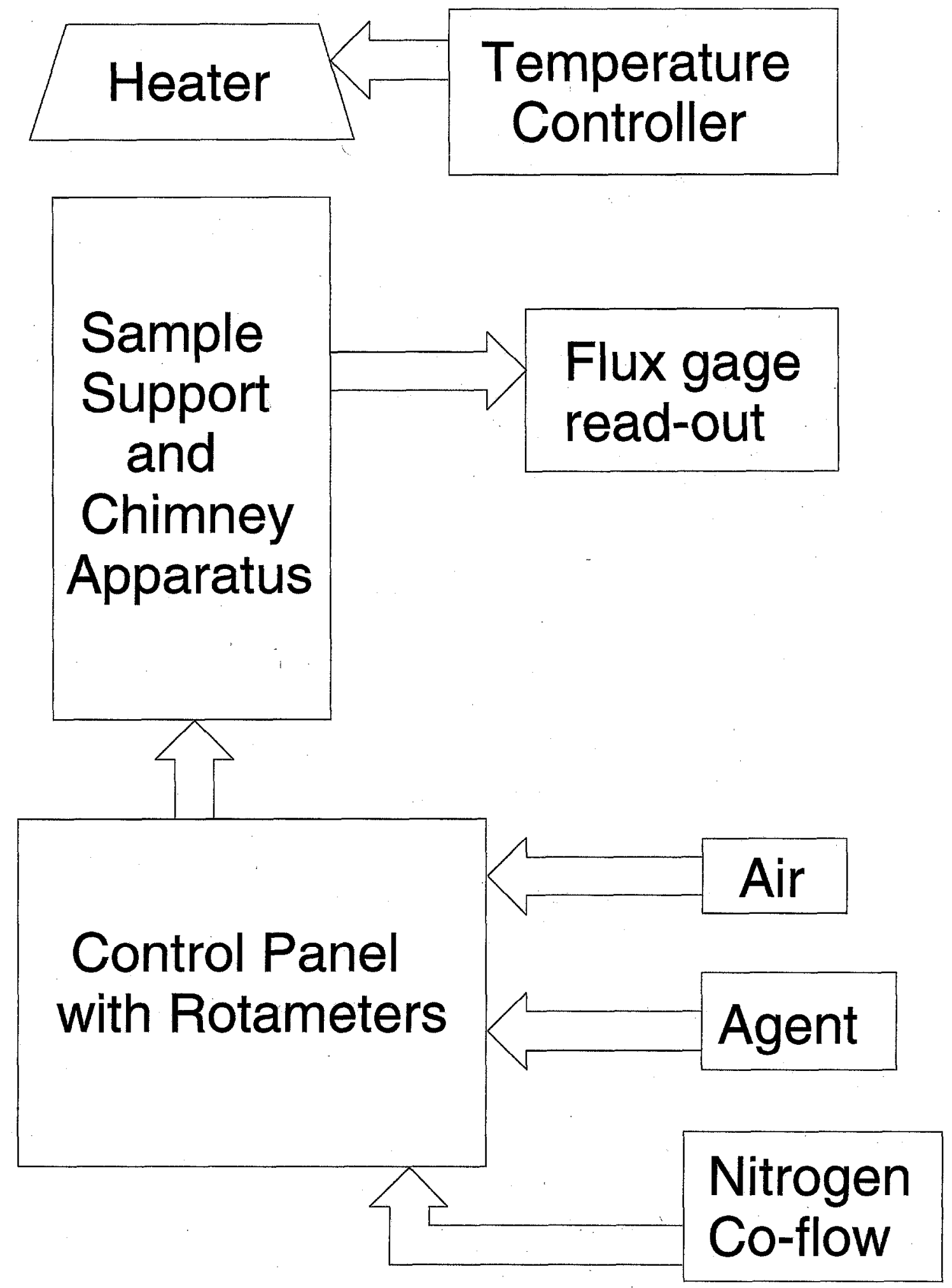

Figure 2. Block diagram of components of REED testing apparatus. 


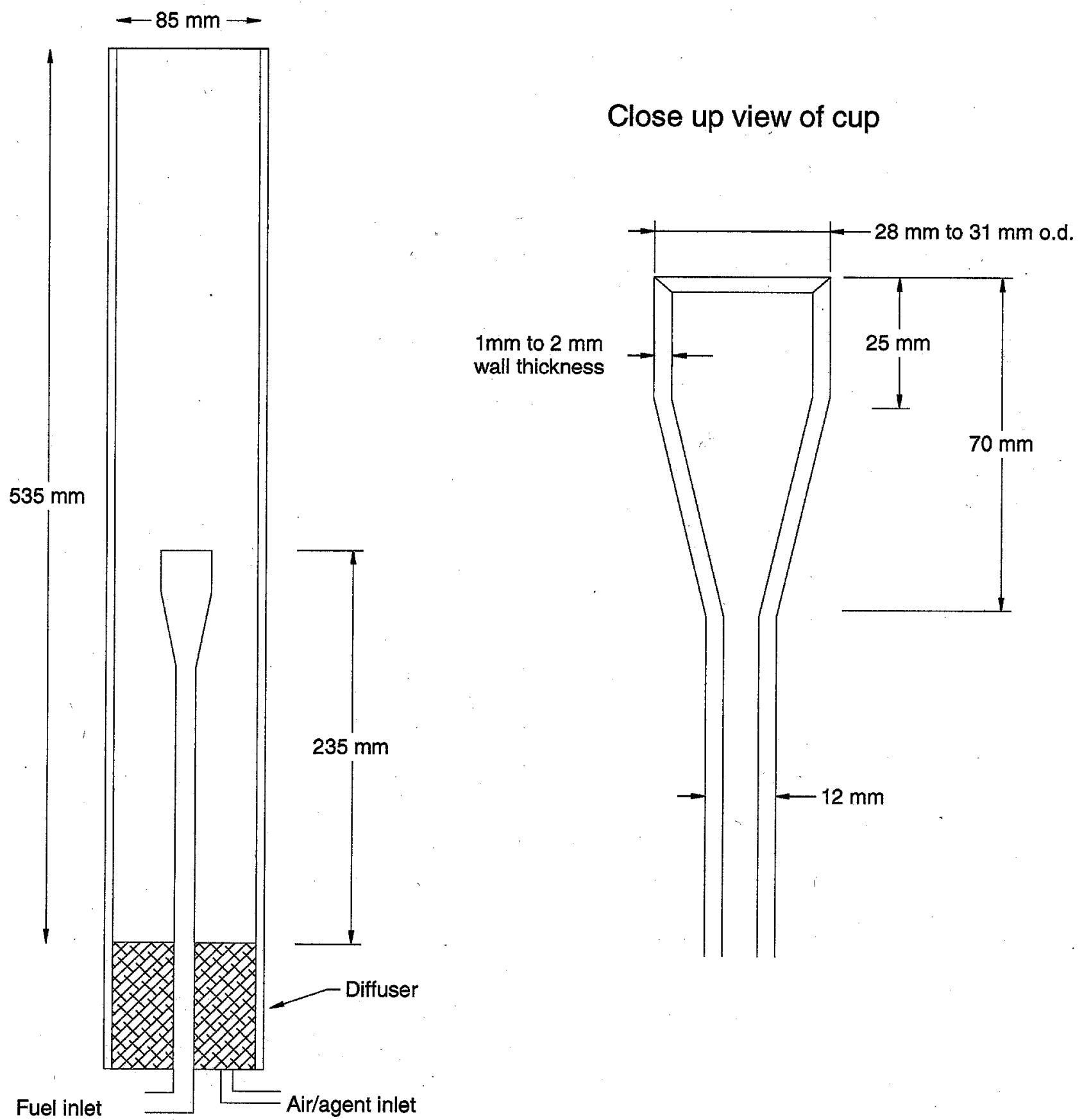

Figure 3. Cup burner diagram. 


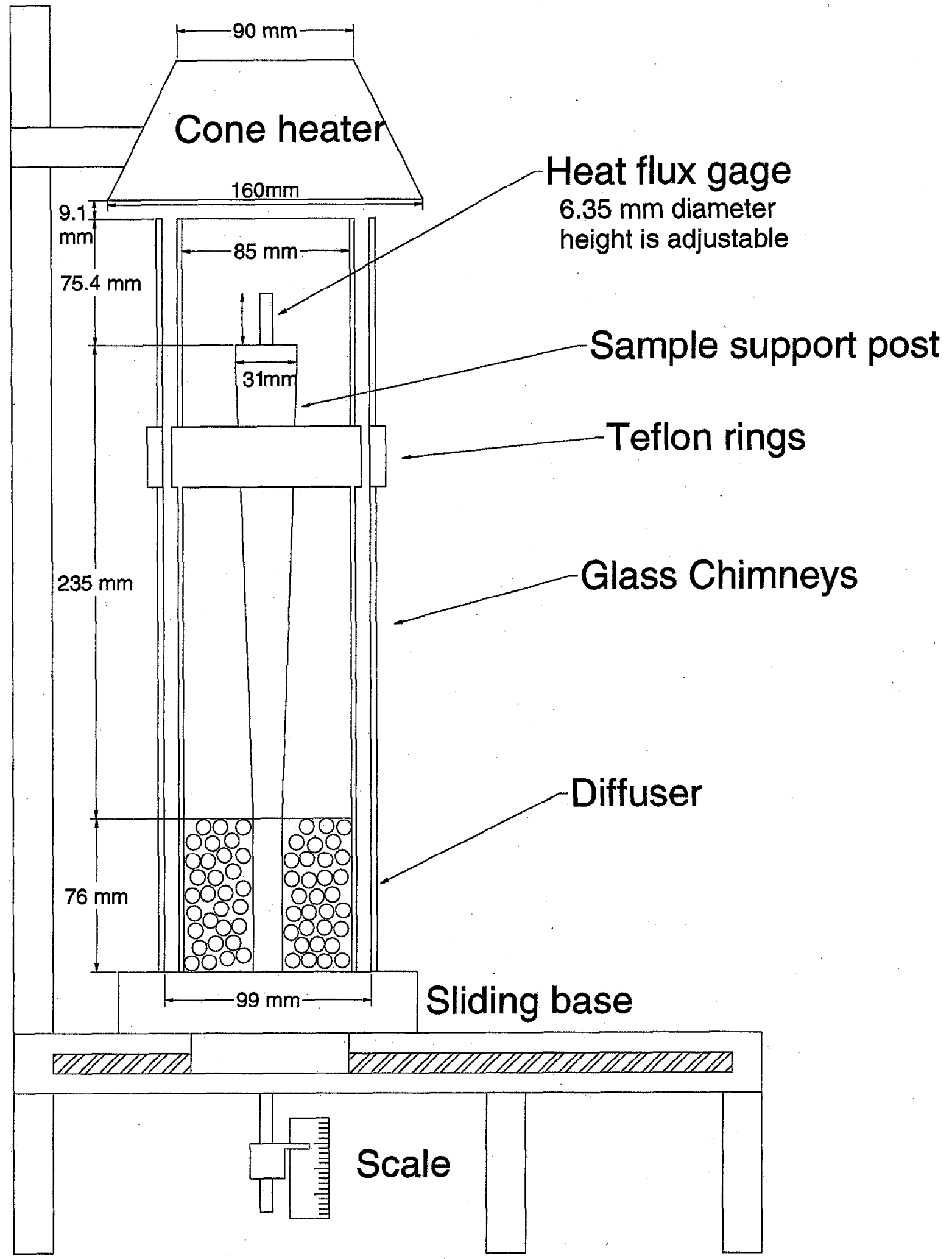

Figure 4. Diagram of REED. 


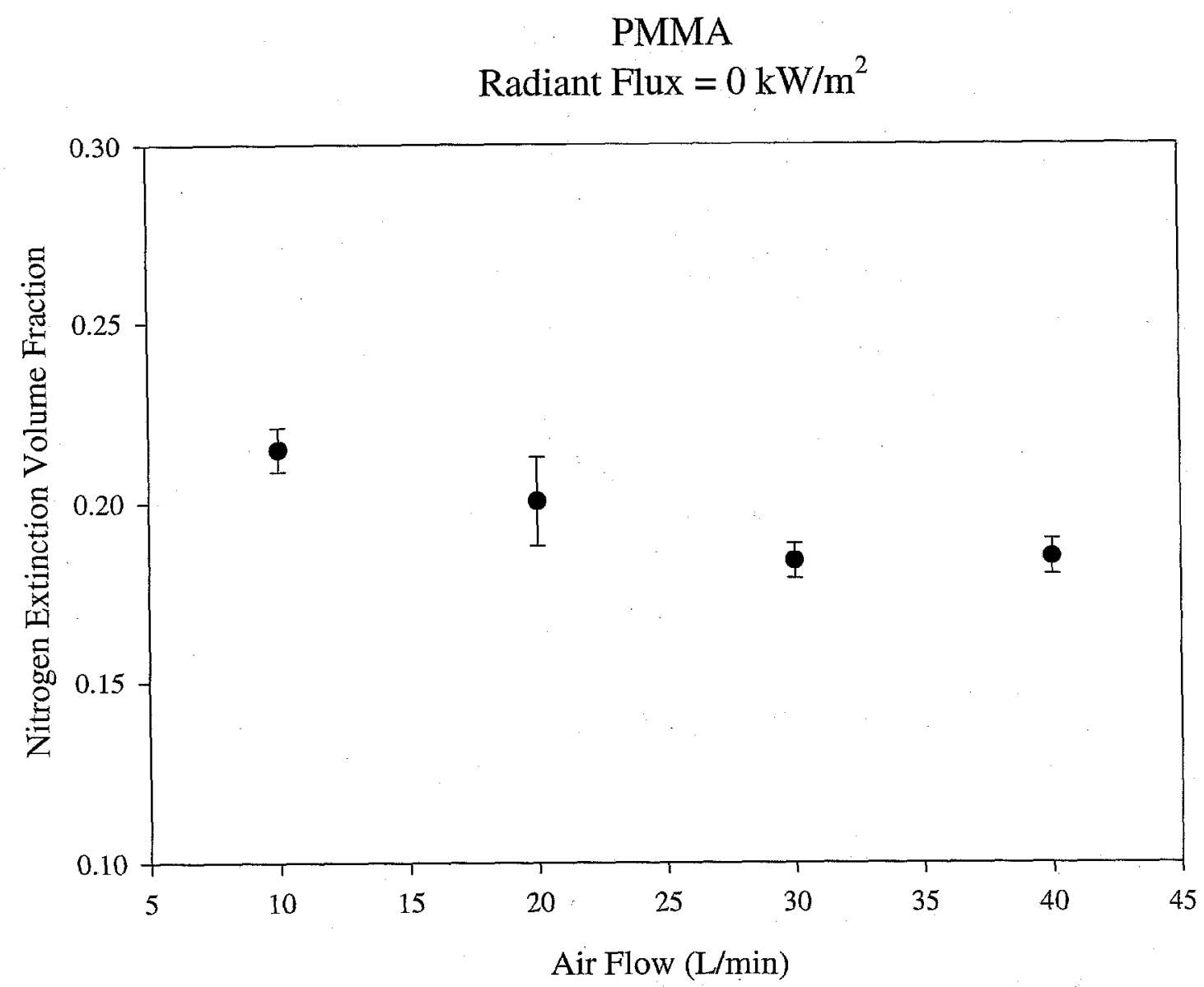

Figure 5. Nitrogen extinction as a function of the voulmetric air flow rate for PMMA with no radiant flux. 


\section{PMMA}

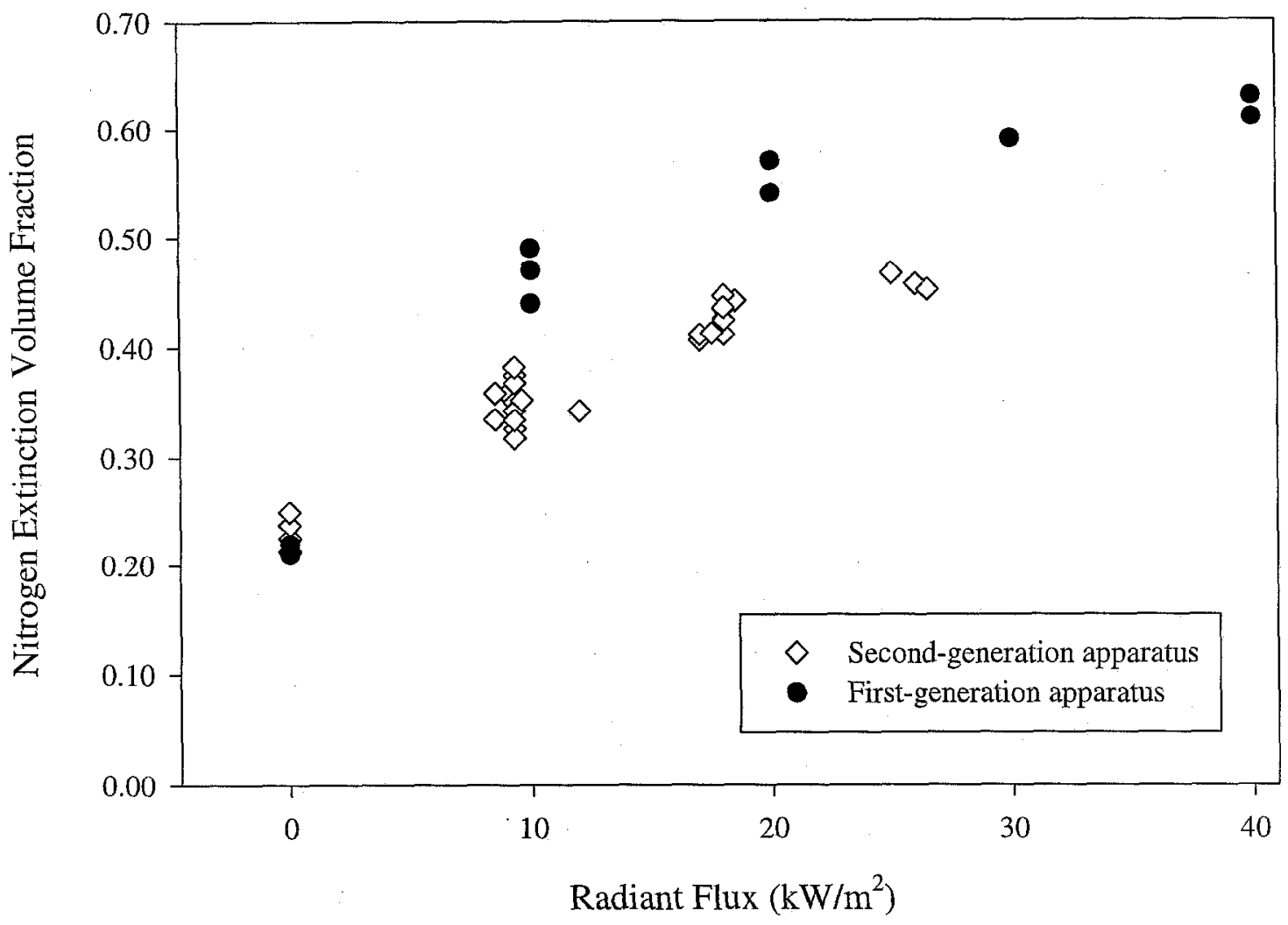

Figure 6. Comparison of the nitrogen extinction data for PMMA obtained using the first-generation apparatus and the second-generation apparatus. 


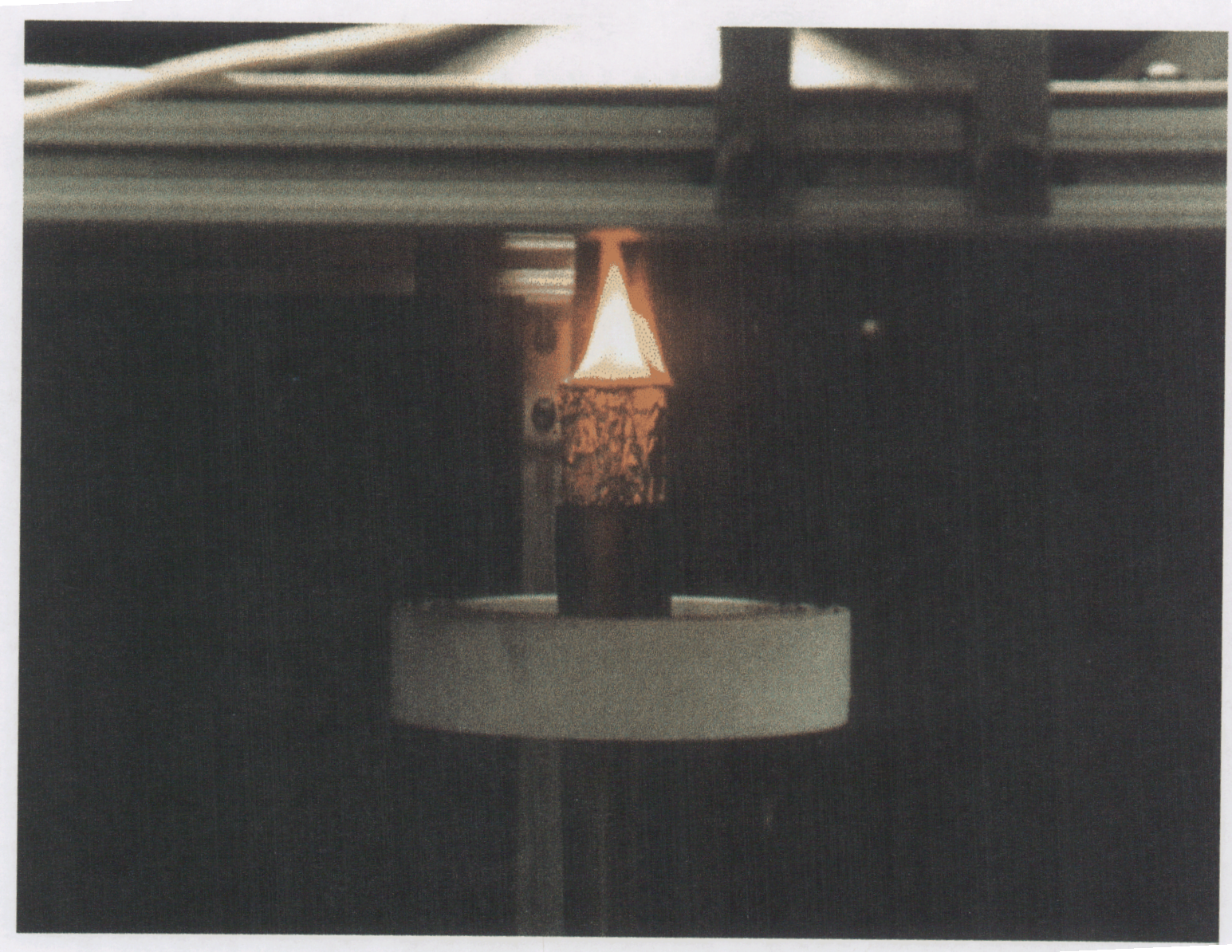

Figure 7. Polypropylene burning as liquid in foil cup 


\section{Polypropylene}

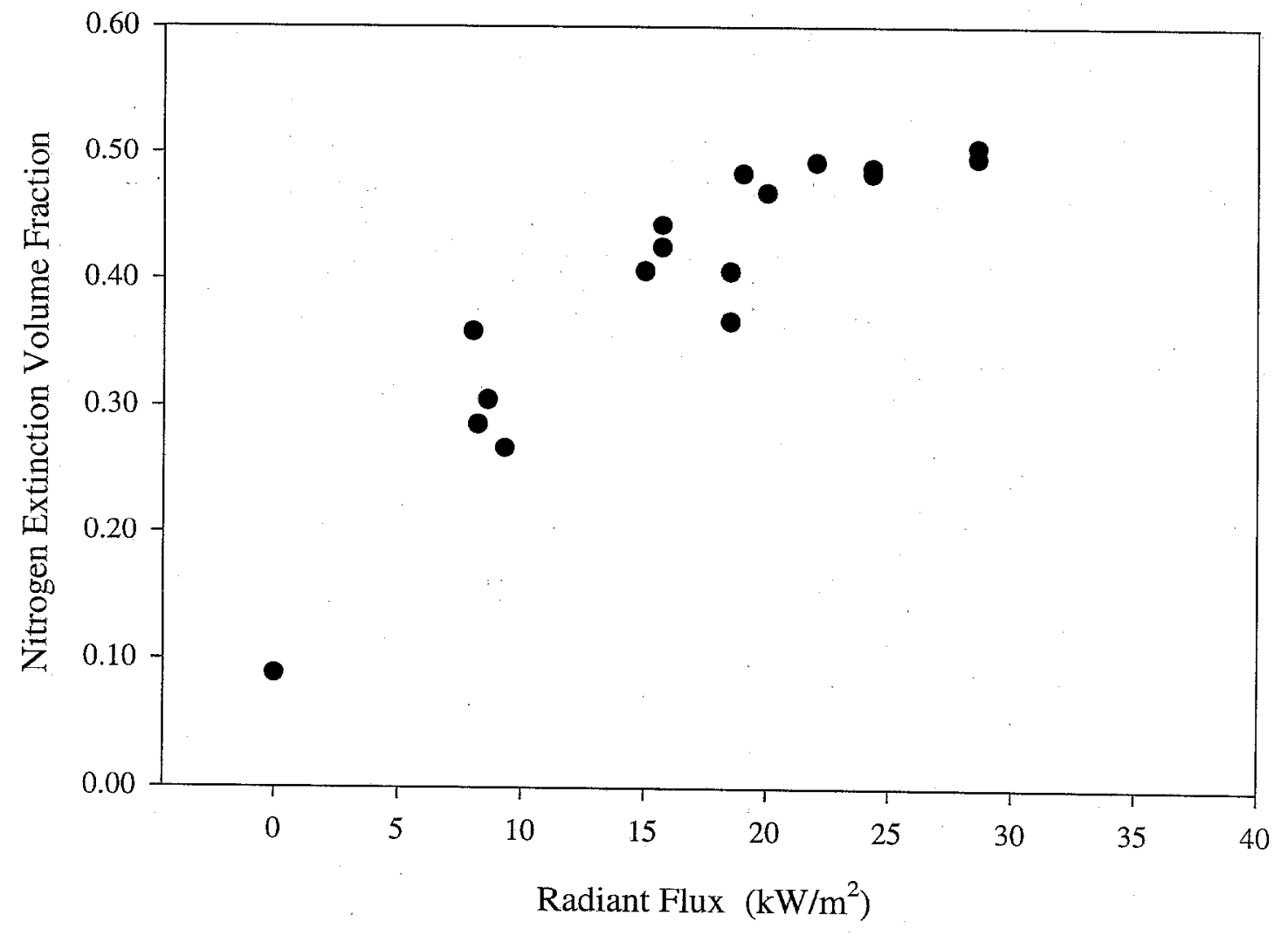

Figure 8. Volume fraction of nitrogen in air at the time of extinction as a function of the radiant flux. Tests conducted at an air flow of $10 \mathrm{~L} / \mathrm{min}$. 


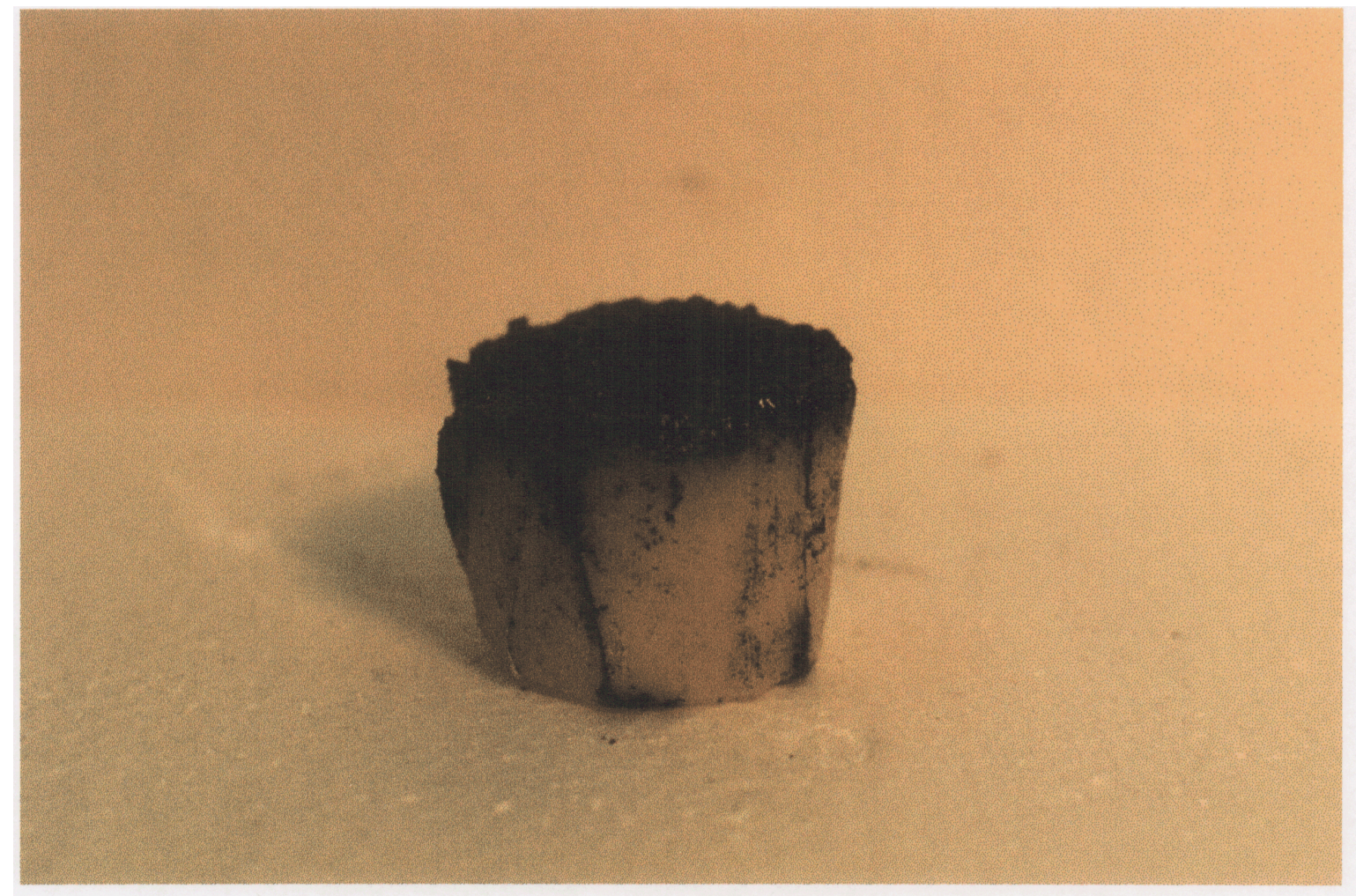

Figure 9. Sample of ABS after testing, with foil removed to show char 


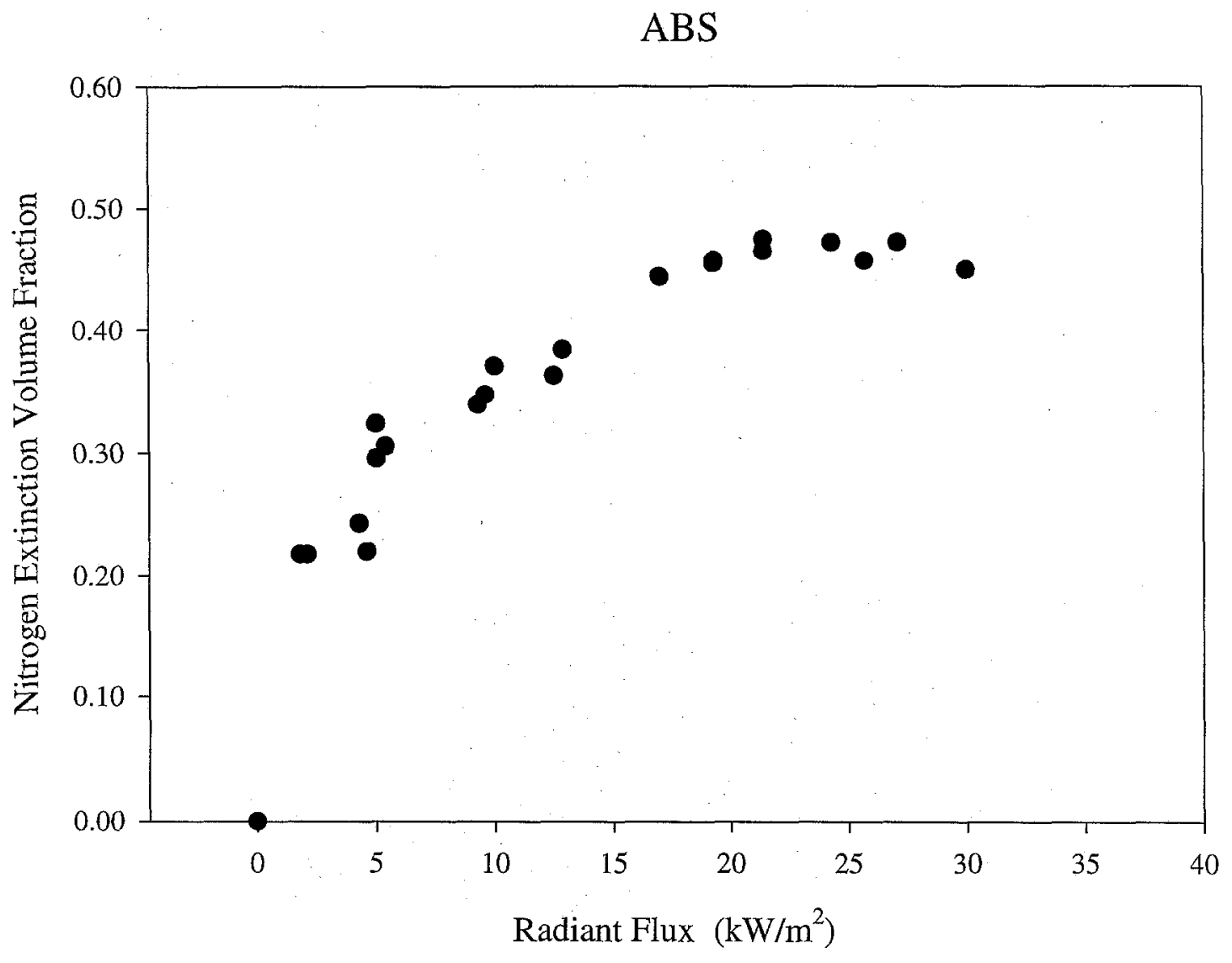

Figure 10. Nitrogen extinction volume fraction as a function of the radiant flux for samples of ABS. Air flow is $10 \mathrm{~L} / \mathrm{min}$. 

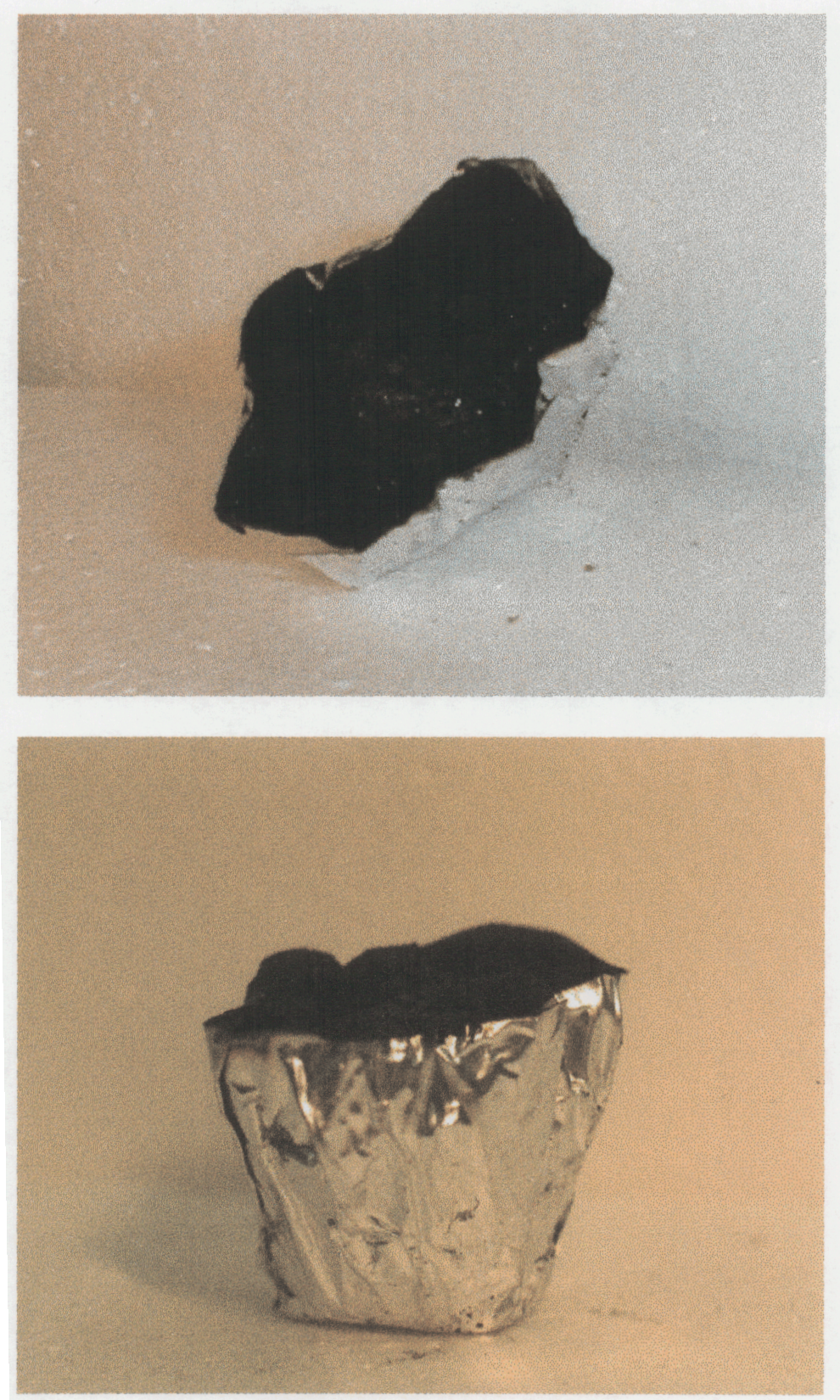

Figure 11. PVC sample after testing. Top view (top) ana siae view (bottom) show spreading of sample due to charring 


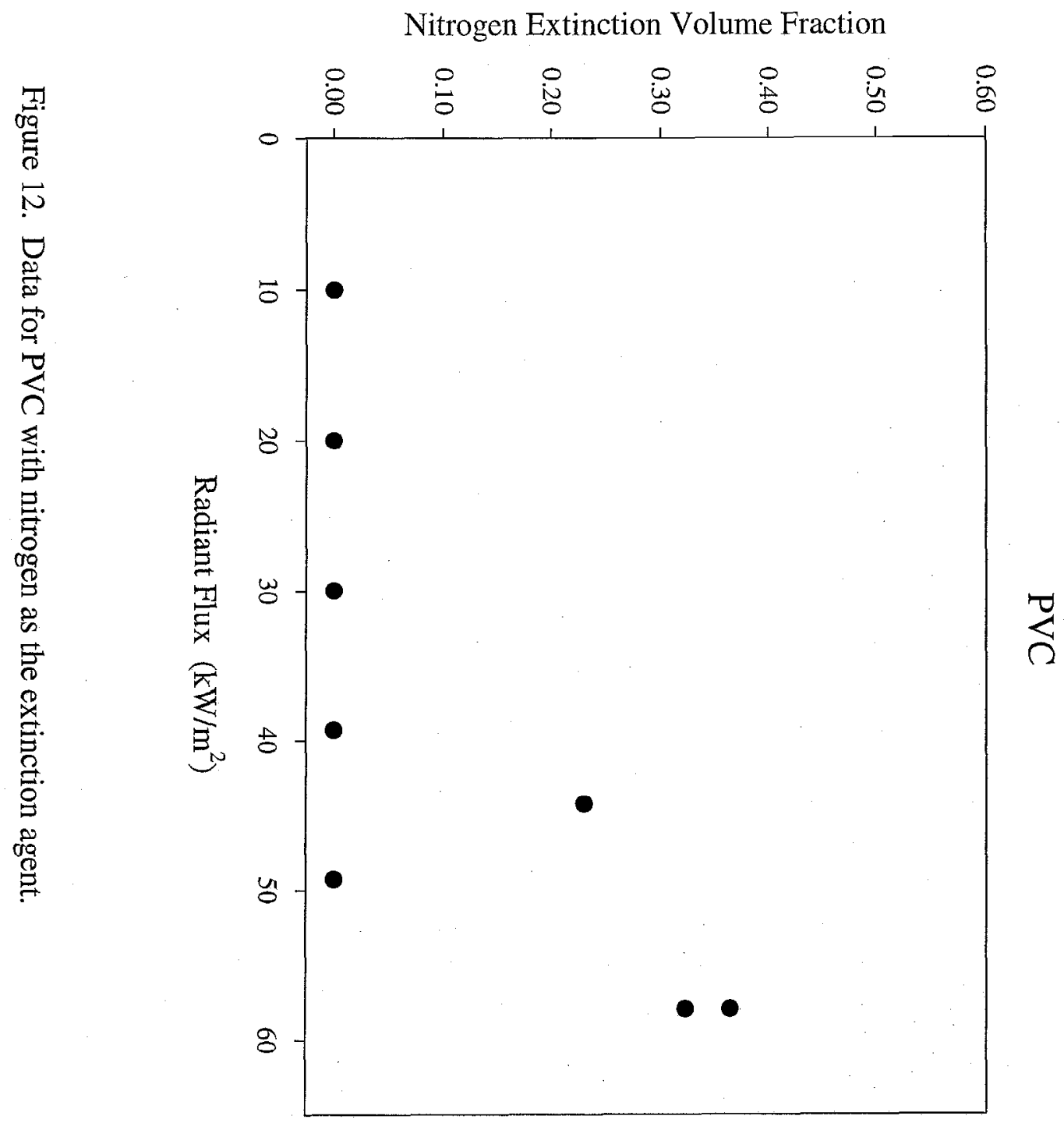




\section{EPDM}

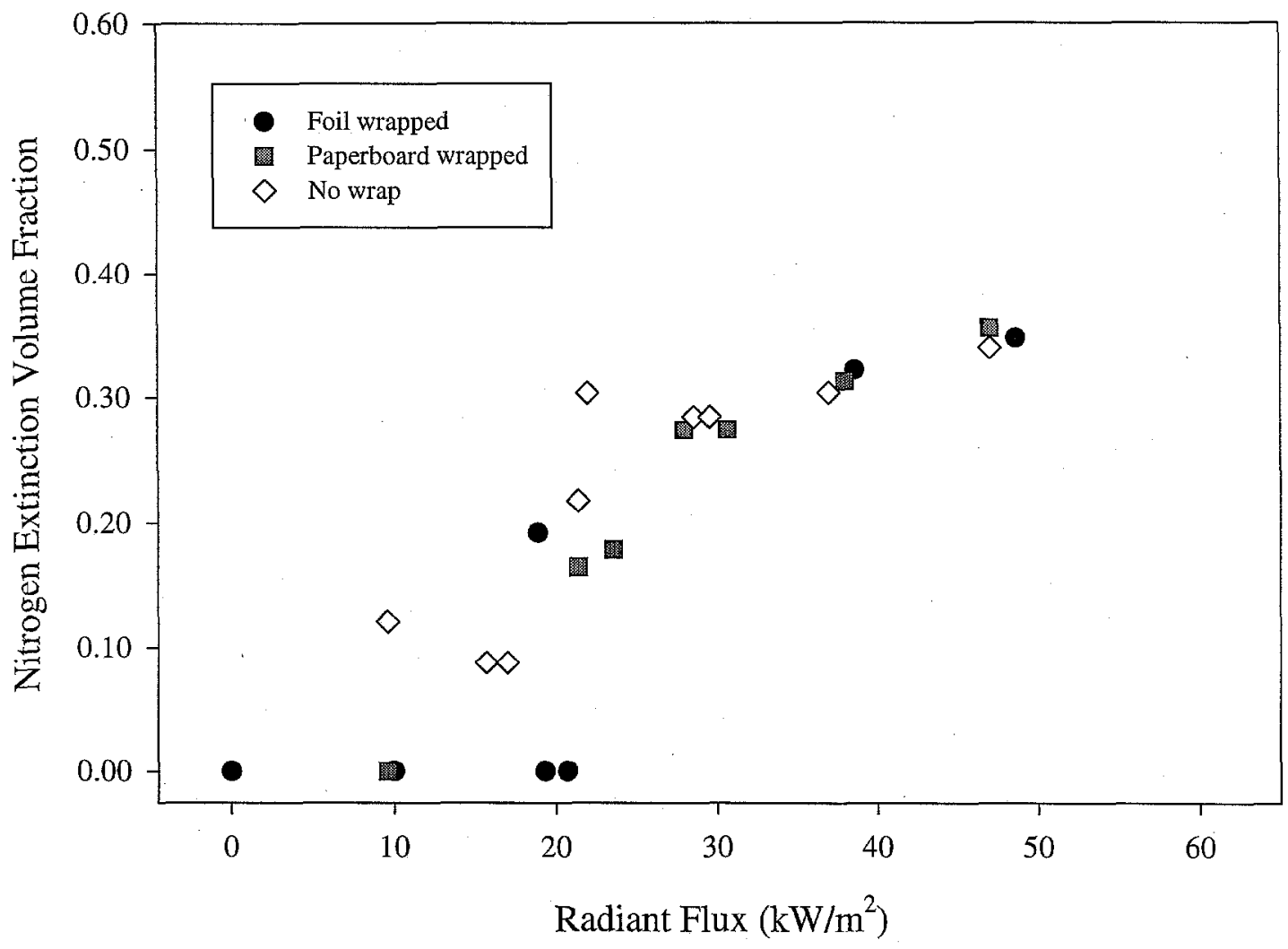

Figure 13. Nitrogen extinction volume fraction as a function of heat flux for EPDM samples with three different wrapping techniques. Air flow is $10 \mathrm{~L} / \mathrm{min}$. 


\section{$20 \mathrm{~kW} / \mathrm{m}^{2}$ \\ $1 \mathrm{~cm}$ inside \\ $\mathrm{T}_{\text {coil }}=650{ }^{\circ} \mathrm{C}$}

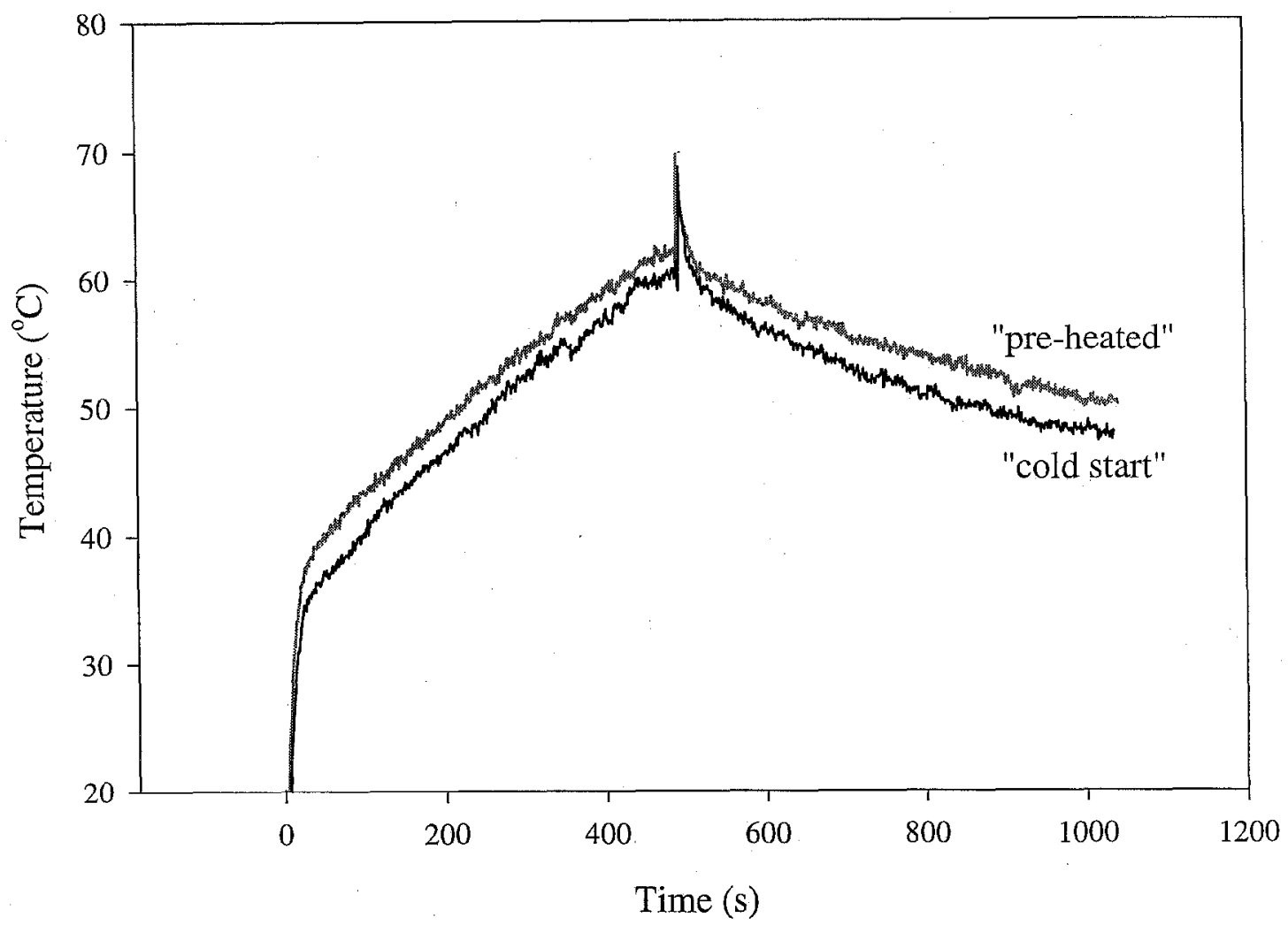

Figure 15. Temperature traces comparing cold start with pre-heated apparatus. Radiant flux is $20 \mathrm{~kW} / \mathrm{m}^{2}$ at top of unburned sample. 